\title{
Linking Knowledge Management, Business Excellence and Innovation Performance
}

\author{
Marianne Gloet \\ University of Melbourne \\ marianne.gloet@unimelb.edu.au
}

\begin{abstract}
This research examined the extent to which the management of knowledge and the application of business excellence frameworks can contribute to innovation performance. A model of Knowledge Management (KM) and Business Excellence (BE) framed the study. Intensive case studies were conducted with six Australian service sector organizations that had won business excellence awards to determine the ways in which a business excellence framework can inform knowledge management practices that lead to sustained innovation performance. Analysis of the data revealed the manner in which the Australian Business Excellence Framework (ABEF) informed knowledge management practices and contributed to innovation in the six service sector organizations. Although the research is preliminary in nature, results indicate that principles of the ABEF shaped KM activities through fostering continuous improvement which in turn encouraged a stronger focus on incremental rather than radical forms of innovation.
\end{abstract}

\section{Introduction}

Innovation performance is highly dependent on the successful management of knowledge in ways that align knowledge with the innovation process [1]. In knowledge-based environments, competitive advantage resides in the acquisition, use and reconfiguration of knowledge in different ways [2]. Rapid changes in the application of technology and the burgeoning global business environment increases the amount of knowledge now available to organizations and increases the speed of innovation processes. This "dynamic reconfiguration of resources" also increases the complexity of innovation, creating shorter product lifecycles and higher rates of new product development [3]. Given that innovation is dependent on the mobilization of knowledge, there is an inextricable link between knowledge and innovation [4]. Therefore, sustainable innovation is dependent on the effective management of human, relational, structural and social capital that underpins modern
Danny Samson

University of Melbourne

d.samson@unimelb.edu.au organizations. Knowledge intensive organizations need sound processes for managing knowledge effectively in order to harness knowledge to support innovation [5] [6]. However, for many organizations, harnessing those knowledge resources effectively remains a mystery, largely because the intangible assets on which they seek to capitalize are difficult to imitate [7]. Despite the ever-expanding literature on innovation in its various contexts, it is still hard to determine which particular organizational activities might lead to innovation performance (IP) and business success. We posit that the effective management of knowledge is one significant way of achieving sustained forms of innovation and performance. This paper therefore also examines the extent to which a framework of business excellence might guide, assist and inform the knowledge management process in order to achieve greater levels of IP. This study is significant because it articulates the close relationship between knowledge and innovation and the ways in which the management of knowledge and the use of business excellence frameworks may contribute to sustained forms of IP.

\section{Theoretical Framework and Relevant Literature}

In today's knowledge-intensive organizations (KIOs), innovation is increasingly seen as the major means by which an organization competes and differentiates itself through innovation. As such, there is a constant need to develop new knowledge related competencies and capabilities in order to grow innovation [8]. Using the lens of resource-based theory, it is clear that knowledge is considered the main source of competitive advantage for KIOs [9] [10] [11] [12] [13] [14]. Moreover, the key to developing dynamic capabilities relating to knowledge assets is dependent on an organization's ability to identify opportunities to achieve sustainable competitive advantage through acquisition, sharing and reconfiguration of knowledge. By sensing, seizing and transforming opportunities related to both tangible and intangible forms of knowledge, dynamic capabilities can be developed to enhance both 
innovation performance and business success [15]. It therefore becomes imperative for organizations to develop sound approaches to the management of knowledge. Since innovation is indelibly linked to knowledge, effective knowledge management (KM) is an important means by which organizations can achieve this sustainable competitive advantage.

At a conceptual level, KM includes definitions of knowledge and descriptions of the underlying principles, practices and frameworks used in organizational contexts. At the level of process, critical concerns include understanding the blueprints for KM and the role of an organization's information technology (IT) infrastructure. Organizational perspectives in KM include organizational culture, structure, strategy, core competencies and strategic capabilities. At the management level, one could examine various management practices such as staffing, employee development, compensation, rewards, leadership styles and motivation. Implementation factors might include KM strategy and approaches, success factors and evaluation issues.

Numerous and increasingly complex representations of concepts, models, frameworks and taxonomies of $\mathrm{KM}$ poses serious challenges in understanding and explaining $\mathrm{KM}$ in organizational contexts. A number of authors recommend integrated approaches to support KM initiatives.to improve business processes, customer relations and innovation opportunities [16] [17]. As Hasan and Handsic [18: 30] state:

$K M$ is always a socio-technical undertaking enabled by social, organizational and technical factors which must be considered in any KM initiative.

Following Handsic and Hasan [18] and Gloet and Samson [19], this research seeks to investigate whether business excellence principles and practices can inform and shape KM practices across technology, people and organizational culture-based approaches to KM, and lead to greater levels of IP (see Fig.1).

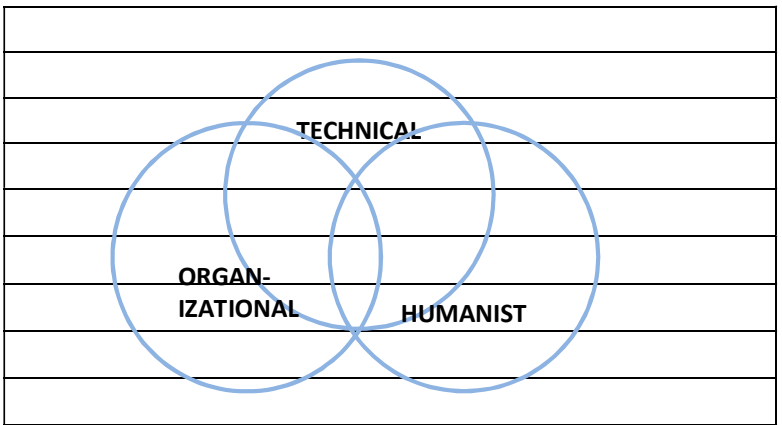

Fig. 1. An integrated framework for approaches to KM
Business excellence frameworks (BEFs) can be described as an integrated set of proven business practices designed to increase business performance across a broad range of organizations. Many of these have their roots in principles of best practice, Total Quality Management, Six Sigma, Business and/or Process Improvement, among others. Examples of well-known BEFs include the U.S. Baldrige Excellence Framework, the European Foundation for Quality Management (EFQM) Framework, the Singapore BEF, Japan Quality Award Framework, the Canadian BEF and the Australian BEF. Although there is some literature that alludes to the potential of BEFs in improving business performance through the management of knowledge and intellectual capital [20] [21] [22] [23] [24], there is a lack of research investigating the potential of BEFs to shape KM practices, particularly those that can contribute to increased levels of IP, and hence sustained business success.

This research focuses on the use of the Australian Business Excellence Framework (ABEF) as a means of guiding $\mathrm{KM}$ practices to achieve IP and business success (see Fig. 2). The ABEF describes the principles and practices of high performance organizations, based on time-honored and tested leadership and management practices [25]. The theoretical framework used for this study is set against two pillars, which brace the integrated approach to KM. The first pillar contains the seven performance categories derived from the guiding principles of the ABEF (Strategy \& Planning; Leadership; Customer \& Market Focus; People; Innovation, Quality \& Improvement; Success \& Sustainability; and Knowledge \& Information). The second pillar relates to the 12 guiding principles of the ABEF (see Fig. 3 ). These guiding principles of leadership and management brace the ABEF while a body of published research supports the approach, thus forming the basis of a unified theory of management [25]. Organizations that adhere to these principles improve their performance significantly and support the innovation process.

The ABEF is a proven model that has been refined and improved over a number of years of implementation and application. If organizations anchor their $\mathrm{KM}$ practices in these principles, arguably, an organization's efforts in KM have a better chance of contributing to increasing IP and overall business performance. The ABEF acknowledges the pivotal role of knowledge and information to business excellence, as these elements form a ring that circles the other six performance categories in the framework. 


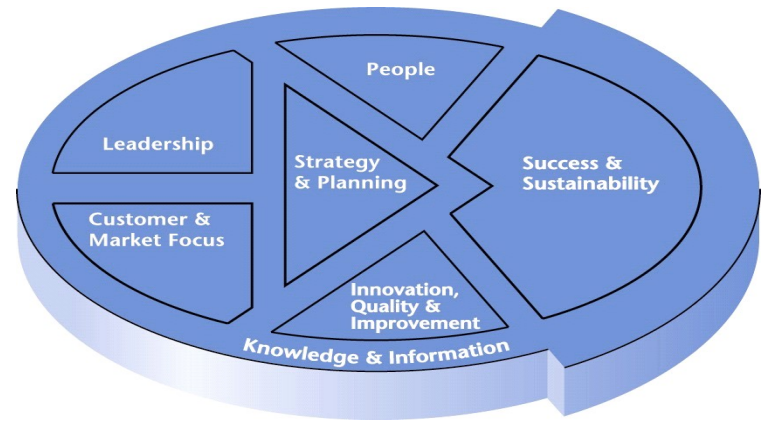

Fig. 2 Australian Business Excellence Framework

The theoretical model underlying this study links Business Excellence principles with KM practices, and denotes how KM success factors that are informed by principles of business excellence can lead to IP (see Fig. 3).

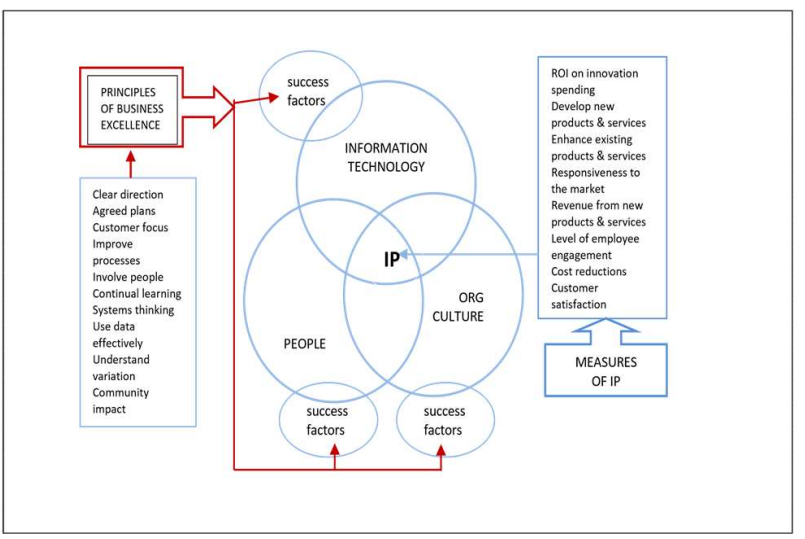

Fig. 3. Theoretical Model

Little consensus exists in the literature concerning the definition and nature of IP. For Ryan [26], IP has two main parameters - the quantity and quality of ideas feeding innovation and the efficiency and effectiveness of the implementation of these ideas circumscribe the innovation process. While the two parameters exist independently within organizations, this research employs "innovation performance" as a surrogate term to capture the benefits that accrues from the management and deployment of organizational resources, including systems, processes, human capital and knowledge capital. Ryan's two parameters, interpreted here as two independent constructs, only deliver benefits to an organization when combined with strategic intent and continuous improvement activities. In effect, IP becomes a significant measure of the value created by an organization. The measurement of innovation performance can take into account a wide range of indicators include assessing diverse areas such as innovation strategy, technology, capability development, processes, people and culture. As such, a range of measures of IP was adopted, based on previous research [27] [28] [29]. These measures are displayed in Fig. 3.

A substantial body of literature speaks to the ways in which the effective management of knowledge enhances and supports activities and processes within each of components depicted in the ABEF (see Fig.2). With regard to strategy, knowledge is critical to developing and adapting innovation strategies under rapidly changing circumstances to foster growth and create value [30]. KM can support creative leadership, develop human and social capital to stimulate innovation within organizations [31], support change management and mediate the relationship between transformational leadership and team-based innovation [32]. When KM is effective, it can also facilitate collaboration and customer engagement to support open innovation [33] and a strong customer focus [34]. KM can also play an important role in serving as a mediator between HRM practices and increased levels of innovation [35] [36].

The people side of KM can also be strongly supported by KM, including through organizational learning linked to technical innovation [37]. Based on a framework of knowledge, organizational learning positively influences both IP and business performance [38]. KM-supported human resource practices can improve organizational innovativeness by rewarding employees for acquiring and sharing knowledge [39] found that organizations improve their innovativeness through rewarding employees for acquiring and sharing knowledge, as well as developing employee capabilities that can support innovation [25].

KM contributes to innovation and sustainability operations through a focus on knowledge, learning and collaboration [41] [42]. KM also enables and improves environmental sustainability practices and processes in organizations [43]. Effective innovation process and project management is dependent on the systematic gathering, sharing and dissemination of knowledge and information in addition to the coordination of knowledge activities [44]. KM provides a backbone of support for information systems and IT innovation [21] [45]. It has been found that an organization's technological performance can be greatly enhanced by a knowledge-based organizational culture [46] [47], and that KM can assist through supporting strong communication channels up, down and across an organization. Kim et. al. [48] found that strong quality management practices with a focus on continuous improvement contributes to innovation. Finally, KM 
can foster a strong customer and market focus through supporting customer relationship management [49] [50] [51].

\section{Methodology}

The following research questions frame the research study:

$R Q 1$. In what ways are KM practices manifested in organizations that have successfully implemented a business excellence framework?

RQ2. To what extent can a business excellence framework shape knowledge management and contribute to innovation performance?

The study focused on the close links between knowledge and innovation and the ways in which both $\mathrm{KM}$ and business excellence principles contribute to IP. The methodology consisted of a literature review and the development of a model linking business excellence and knowledge management to measures of IP, followed by a qualitative study. This qualitative research involved six case studies of Australian service sector organizations. Adhering to advice about the importance of the initial selection of cases to improve reliability [52], organizations that had won an Australian Business Excellence Award were chosen for this research. These awards identify outstanding organizations in Australia, with the business and service communities recognizing their value as significant and of international standing. ABEA winners provide a quality pool of potential organizations actively engaged in best practice and business excellence to support innovation. Since 'knowledge' and 'information' circumscribe the framework, holders of an ABEA should provide appropriate cases for study in the context of KM and innovation performance. The research involved a series of in-depth interviews with a range of managers and employees in each of the six organizations.

The purpose of this study was not to offer generalizations based on statistical analysis, but rather to generate a bank of rich data to identify major themes and subthemes [53]. Based on a review of the literature, the interview protocol was developed using overarching themes and guiding questions. A series of stem questions relating to KM and business excellence activities yielded information from respondents concerning the ways in which $\mathrm{KM}$ and business excellence activities were manifested in their organizations. The interviews yielded multiple perspectives concerning the $\mathrm{KM}$ and business excellence activities and their impact on innovation performance. A method of textual analysis, frequently utilized in social science research, used a coding system where data was placed into some predetermined categories by the researchers and grouped across a range of patterns or themes that emerged from the interviews [52]. An interpretive method was used to identify themes in the data [54] as part of the cross-case analysis [55].

\section{Case Study Findings}

The following case studies provide an overview of $\mathrm{KM}$ and business excellence activities to support IP.

\subsection{Case 1 - 'Legal Services'}

This organization is the main provider of civil legal services to a large state government in Australia. At Legal Service (LS), all 85 employees are public servants; of these, 45 are solicitors who serve as officers of the State Supreme Court. Five separate branches of the organization offer legal services, including in the areas of administrative and property law, as well as legal services to the police force and a full range of litigation on behalf of the courts. The senior management of LS recognizes that knowledge assets are fundamental to its mission of achieving excellence in the provision of legal services to the government.

Over the years LS has adopted formal business planning processes, as well as a number of quality and continuous improvement initiatives. This led to the appointment of a specialist KM manager to oversee KM initiatives, especially the application of knowledge, to achieving the organization's goals and objectives. LS is subjected to considerable business pressure. High fees, fierce competition and high service expectations characterize the legal services market. In this competitive environment, maintaining an exceptional level of knowledge and service is seen as a chief source of competitive advantage, and managers highlighted the necessity to develop sound HR structures and processes to support KM initiatives such as building a knowledge-sharing culture, promoting learning, using smart processes and effective technology.

$\mathrm{KM}$ provides strong support for HR functions, communication channels, and the processes of knowledge creation, sharing and utilization. As an enabling tool, technology connects people with data, information and with one another. The prevailing philosophy is that "technology fits people and processes - not the other way around". On the systems side, a document management system facilitates the sharing of knowledge and information. All staff have desktop access to relevant IT platforms and receive regular training about how to access the knowledge and information relevant to their work.

With respect to the links between $\mathrm{KM}$ and innovation, LS regards innovation as a series of incremental improvements that create opportunities to 
streamline processes and improve service delivery. Smart applications of technology and studious management of knowledge strengthens service delivery. Innovation, therefore, assumes the guise of continuous improvement initiatives. Legal services and issues do not change rapidly and in the conservative environment of the law, large-scale radical forms of innovation do not apply.

\subsection{Case 2 - 'Revenue Services'}

Revenue Services (RS) is an independent service agency acting under a framework agreement between the Treasurer, the Secretary of the Department of Treasury and Finance (DTF) and the Commissioner of State Revenue in a large Australian state. Employing over 400 staff, the organization describes itself as a "knowledge and information centric organization" that administers taxation legislation and collects a range of taxes, duties and levies. Core functions of the organization include collecting, maintaining and disseminating information from both external and internal clients and sources. In this environment, a strong focus on managing data and information and a genuine commitment to quality processes and compliance are essential. Initial iterations of $\mathrm{KM}$ to service these functions were extensions of TQM, ISO and other quality processes.

To ensure efficient and effective revenue collection, approaches to KM utilize new and alternative technologies to support the existing customer interface. Increased productivity through time and cost savings for taxpayers is an anticipated payoff from effective KM initiatives. KM helps target projects and ensures that a strong compliance culture permeates the organization. Knowledge creation and retention is a key aspect of organizational development at RS. KM also contributes to professional relationships through processes that maintain high levels of customer service, effective inter-office interactions and strong cooperation across other jurisdictions and government departments.

At RS, knowledge is considered essential to innovation. Given the nature of the business model, innovation is focused on two main areas - compliance and service provision. Innovation for compliance relies heavily on extensions of TQM and ISO systems that were previously adopted and which now form a strong backbone of the organizational culture. Innovation in support of service provision is also characterized more by small-scale improvements rather than large-scale radical change. KM at RS therefore supports ongoing, small-scale continuous improvement through monitoring, reporting and tracking of performance across a variety of pre-set indicators. This streamlining of processes and cultivation of information reflects a view of innovation as being closely associated with continuous improvement, rather than with larger scale discoveries and developments.

\subsection{Case Study 3 - 'Ambulance Services'}

Ambulance Services (AS) is responsible for the delivery of ambulance services in a large state of Australia. The organization employs approximately 3,000 people, including 2,700 paramedics and 300 ambulance and allied staff. Some 1500 volunteers also assist in Local Ambulance Committees. The organization considers its people to be the driving force behind its success and has a strong commitment to best practice principles across both office and field contexts. AS maintains a sophisticated training and development facility which delivers clinical education and development programs. Education programs adhere to nationally recognized competency standards and are innovative. The organization also provides community education programs in First Aid, Injury Prevention and CPR to over 35,000 people per year. In addition, Ambulance Services coordinates the delivery of aero-medical evacuations throughout the state.

As a way of realizing the highest possible standard of ambulance (pre-hospital) care, KM supports the modernization and upgrading of ambulance services and functions in areas that include education, training, equipment and technology. KM emerged as an indispensable element in building partnerships across communities and jurisdictions. KM also became a key strategy linked to the continual improvement process within the service. The service adopted the ABEF to guide this process because both knowledge and information management are fundamental components of the model.

For ambulance officers today, pre-employment tertiary qualifications are mandatory because of the complex medical interventions and treatments they are required to perform. A logical step was to adopt KM systems that could track and measure the nature and impact of these interventions. As such, KM is pivotal in supporting initiatives across the organization in the designated areas of Research; Education; History and Heritage; Policy, Process and Technology; and Performance Measurement. In addition, a growing global interest in risk management globally prompted Ambulance Services to tailor their KM efforts toward initiatives to reduce risk. Clearly, the safe transport and care of patients entails a high degree of risk and improving response times, for example, reduces risk for both the patients and the organization.

In order to facilitate greater levels of stakeholder engagement, AS began to tie their KM efforts more closely to HR and people management. Since earlier iterations of $\mathrm{KM}$ at the service were focused more on the use of technology to support the organizational 
mission, senior management felt the need to expand the scope of KM into areas such as the development of KPIs to support performance management and employee development. It was felt that engaging in knowledge work and supporting the strategic thrust of KM within the organization should be rewarded in tangible ways. KM was seen as a means by which to ensure that expectations regarding desired employee behaviors were clearly communicated across the organization. KM was also seen as a means by which AS could develop individual, team and organizational capabilities across the organization.

Characterized by a demand for a high level of innovation in technology, medical treatment and service delivery, the service views KM as "a bonding agent bringing remote sites together". The link between KM and innovation revolves around continual improvement of processes that acquire knowledge and apply it to suit specific operational contexts. AS is very mindful of the need to keep abreast with cutting-edge developments in the health field, and KM plays a critical role in ensuring that information about new developments in technology and service delivery are accessed quickly. However, small scale, incremental improvements in all processes also forms part of the relationship between KM and innovation.

\subsection{Case Study 4 - 'Environmental Monitoring'}

Environmental Monitoring specializes in the provision of third party monitoring and management of gasoline storage installations for the retail sector. Most of EM's clients are from the retail gas sector with some others in industries that store hazardous materials or who are subjected to regulatory license conditions. EM detects leaks in underground petroleum installations at a very early stage. Early detection results in less damage to the environment and considerable cost savings for the client. The organization currently monitors over 11,000 tanks across some 3,600 locations throughout Australia, New Zealand, the UK, Ireland, Europe and elsewhere. EM trades on experience, software and specialized monitoring techniques. Third party monitoring is increasingly important in a market where environmental protection monitoring is becoming commonplace. In addition to detecting leaks in underground petroleum storage systems, the company also provides management services to the petroleum and industrial sectors.

Employing 30 people, EM faces significant challenges in managing knowledge and information resources. Working with a UK partner requires EM to maintain clear lines of communication and live network connections at all times. These links involve vast distances and different time zones. Similar factors can also impinge on client relationships in Australia. The careful management of time and distance factors is essential. Intellectual property looms large as a major concern for EM with the organization constantly required to protect its investment in intellectual capital. Knowledge management is a risk management strategy in this context.

Information technology is a major business function. In monitoring wet stock leakage, the company is highly dependent on reliable IT hardware, software, infrastructure and information management systems. Data, information and knowledge provide the backbone of the management services provided to clients in the petroleum and industrial sectors. The company's approach to KM highlights the importance of people management, and teamwork characterizes the working atmosphere at EM. Employees describe $\mathrm{KM}$ as "focused on people" and supporting an environment of empowerment, shared accountability and responsibility. The KM program houses a sophisticated suite of learning, training and coaching tools, which are highly valued by employees and there is a strong commitment to continual learning with inhouse and outside training conducted on a regular basis. Although knowledge creation, sharing and dissemination are fundamental KM processes, the CEO considers creating new knowledge as most essential to the business. EM's business strategy depends heavily on developing innovative tools and techniques for the petrol monitoring industry.

As an organization not far removed from its startup days, EM maintains an extremely close watch on the KM - innovation interface. The necessity to secure a reputation for quality and gain competitive advantage quickly through the development of new products and services is ubiquitous at EM. Research and development is a critical link in the KM-innovation chain. Knowledge management also supports smallscale incremental innovation through improving measurement techniques and quality improvement initiatives.

\subsection{Case Study 5 - 'Real Estate Co.'}

Founded in 1985, this real estate firm is now a leading agency in Australia. Winning numerous awards in customer service, quality and business excellence, Real Estate Co. (RECo) is strongly committed to providing excellence in customer service through innovation and systematic, cost effective business practices. Strong growth led to expansion and RECo now has in excess of one hundred employees across four office locations. The Managing Director of RECo asserts that knowledge is essential to gaining and maintaining competitive advantage in the real estate market and acknowledges that KM is fundamental to RECo's business model. Two main 
drivers for introducing $\mathrm{KM}$ came from the organization's vision statement to commit to excellence in customer service (we will provide service to our clients of a standard unmatched in real estate) and the need to innovate (the industry is led by our unprecedented innovation). RECo recognized the need for effective KM to support their quest to provide the best quality and most innovative customer service possible in a highly competitive market. A strong IT infrastructure and administrative system supports the $\mathrm{KM}$ approach at RECo. In addition, a well-structured administrative system ensures that all services meet the organization's legal requirements. In many respects, KM at RECo is an extension of the company's long standing commitment to continuous improvement, and quality initiatives at RECo depend heavily on KM support. Knowledge management manifests itself in HR practices, particularly in areas concerned with performance management, staff development and induction. In addition, RECo endeavors to develop and maintain a strong internal team-based culture that supports and values learning and knowledge sharing. The team culture at RECo is all-encompassing. The overall organizational culture also values highly the traits of ingenuity, liveliness and agility. Senior management believes these elements give the organization a "certain degree of nimbleness". This culture of adaptability allows for prudent risk taking and a willingness to question certain business assumptions.

A cornerstone of RECo's success is its approach to $\mathrm{KM}$. Knowledge management underpins innovation at RECo, an organization proud of their innovative products and services, especially the use of various technology applications to spearhead innovation. These applications include geographic imagery, social media, internet and applied virtual technologies.

\subsection{Case Study 6 - 'Regional City Council'}

This Regional City Council (RCC) supports one of Australia's fastest growing regional cities. The city services a regional population of around 160,000 . Its position on the main Australian transport and communications corridor makes it an attractive business location. The city's proximity to the numerous wineries and alpine ski resorts makes it a desirable leisure and lifestyle destinations. Currently, seven elected commissioners serve on the Council, which takes responsibility for policy development, strategic planning and civic leadership and regional management. At the time of writing, RCC had 410 employees and engaged some 242 volunteers.

The city served by RCC prides itself on being a "Learning City", a term frequently cited in its Annual Reports, marketing and publicity materials. In the light of social and technological change, the Learning City concept creates a cohesive community to face the challenges brought on by these changes and as such, $\mathrm{RCC}$ recognizes the pivotal role of KM in this regard. While KM manifests itself in a variety of ways at $\mathrm{RCC}$, its purpose is to share knowledge and provide opportunities to create new knowledge. An open environment and the opportunity for both virtual and face-to-face meetings enhance interaction among individuals and teams. Team structures are important at RCC. Regular team forums provide vehicles for sharing ideas, challenging assumptions and "finding better ways of improving council services". Internal and external focus groups and internal customer surveys generate data that supplements these forums.

There is a strong culture of organizational selfassessment at RCC based on the criteria of the ABEF. Knowledge management enablers introduced at both the grassroots and community levels include storytelling and narratives. These are strongly encouraged as a means of spreading good news stories relating to various WCC learning initiatives and projects within the greater community. A similar program, Bright Lights, displays the work of outstanding employees and volunteers at RCC. On the HR side, KM supports a wide range of training, learning and development activities.

The RCC considers process improvement teams as a means by which to link KM and innovation. The process improvement teams are indicative of RCC's view of innovation and the links between innovation and KM. Rather than large-scale inventions or discoveries; incremental improvements and small-step processes that support continuous improvement within the organization constitute RCC's view of innovation. $\mathrm{KM}$ helps to identify knowledge gaps and pinpoint steps to close these gaps. Sharing existing knowledge generates new knowledge, often alleviating the need to bring in experts or consultants to solve business problems.

\section{Discussion}

The six organizations in this study are strongly committed to KM, with significant investment in time and resources across KM activities. Each organization reported a wide range of benefits achieved from their KM initiatives. Many benefits influence the bottom line of the organizations, including increased profits, improved operating efficiencies and ongoing cost savings. KM also contributes to customer satisfaction through creating ongoing efficiencies and supporting continuous improvement in all six organizations.

Respondents from the six organizations felt that $\mathrm{KM}$ initiatives made a significant contribution to quality and small-step innovation. On the quality side, this includes supporting better business planning, 
more informed decision making leading to better business processes and better quality overall. Enhanced data access, data mining techniques and improved information management allowed higher benchmarks for service, delivery and response in most of the cases. In turn, this led to the strengthening of continuous improvement efforts and to innovation initiatives, particularly those of the small scale, incremental variety. Table 2 provides an overview of the results of the cross-case analysis, indicating the extent of various dimensions of KM practice across the six ABEF performance categories for the case study organizations.

\begin{tabular}{|c|c|c|c|c|c|c|}
\hline Case & 1 & 2 & 3 & 4 & 5 & 6 \\
\hline \multicolumn{7}{|l|}{ KM DIMENSION } \\
\hline Use of smart technology & $\sqrt{ }$ & $\mathrm{V}$ & $\sqrt{ }$ & $\sqrt{ }$ & $\sqrt{ }$ & $\mathrm{V}$ \\
\hline Customized ICT & $\mathrm{V}$ & V & $\sqrt{ }$ & $\mathrm{V}$ & $\mathrm{V}$ & $\mathrm{V}$ \\
\hline Heavy investment in tech & $\mathrm{V}$ & $\sqrt{ }$ & $\sqrt{ }$ & $\sqrt{ }$ & $\sqrt{ }$ & $\sqrt{ }$ \\
\hline Calculating ROI on KM & & $\sqrt{ }$ & & & & \\
\hline Focus on ICs as driver of IP & & & & $\sqrt{ }$ & & \\
\hline Focus on sound info mgmt & $\mathrm{V}$ & $\sqrt{ }$ & $\sqrt{ }$ & $\sqrt{ }$ & $\sqrt{ }$ & $\sqrt{ }$ \\
\hline Building K sharing culture & $\mathrm{V}$ & & & & $\mathrm{V}$ & $\sqrt{ }$ \\
\hline $\begin{array}{l}\text { Tracking quality } \\
\text { performance }\end{array}$ & & $\mathrm{V}$ & $\sqrt{ }$ & $\sqrt{ }$ & $\sqrt{ }$ & \\
\hline Monitoring for $\mathrm{Cl}$ & & $\sqrt{ }$ & & $\sqrt{ }$ & & $\sqrt{ }$ \\
\hline Capturing tacit knowledge & & & & & $\mathrm{V}$ & \\
\hline Boundary spanning & $\mathrm{V}$ & & $\mathrm{V}$ & & $\mathrm{V}$ & $\sqrt{ }$ \\
\hline Communication & V & $\mathrm{V}$ & $\mathrm{V}$ & $\sqrt{ }$ & $\mathrm{V}$ & $\mathrm{V}$ \\
\hline Employee engagement & $\sqrt{ }$ & & $\mathrm{V}$ & & & \\
\hline $\begin{array}{l}\text { Performance } \\
\text { management }\end{array}$ & $\mathrm{V}$ & $\sqrt{ }$ & & $\sqrt{ }$ & & \\
\hline Supporting change mgmt & & & & & $\mathrm{V}$ & \\
\hline $\begin{array}{l}\text { Senior mgmt. support for } \\
\text { KM }\end{array}$ & $\sqrt{ }$ & & & $\sqrt{ }$ & $\mathrm{V}$ & 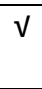 \\
\hline $\begin{array}{l}\text { KM to support service } \\
\text { delivery }\end{array}$ & $\sqrt{ }$ & $\sqrt{ }$ & $\sqrt{ }$ & $\sqrt{ }$ & $\mathrm{V}$ & $\mathrm{V}$ \\
\hline Strategic focus on KM & $\sqrt{ }$ & $\mathrm{V}$ & & & $\mathrm{V}$ & $\sqrt{ }$ \\
\hline KM as risk mgmt. strategy & & & $\mathrm{V}$ & $\mathrm{V}$ & & \\
\hline $\begin{array}{l}\text { LEGEND } \\
\text { Case } 1 \text { - Legal Services } \\
\text { Case } 2 \text { - Revenue Services } \\
\text { Case } 3 \text { - Ambulance Services } \\
\text { Case } 4 \text { - Environmental Monitc } \\
\text { Case } 5 \text { - Real Estate Co. } \\
\text { Case } 6 \text { - Regional City Council }\end{array}$ & ring & & & & & \\
\hline
\end{tabular}

Table 1. Overview of cross-case analysis results

Certain dominant themes arising from the crosscase analysis include heavy investment in technology, supporting the use of smart and sophisticated forms of technology, including customized ICT systems. All six organizations had a strong focus on KM to support training and capability development activities, as well as service delivery - the latter element reflecting a strong customer focus consistent with the ABEF. Most of the organizations exhibited senior management support for KM, as well as a strategic focus on KM. Boundary spanning and communication were found to be significant KM activities. In most organizations $\mathrm{KM}$ played a role in tracking quality performance. Only half the case organizations demonstrated a link between KM and performance management, most often manifested in rewards for knowledge work. Less frequently reported $\mathrm{KM}$ practices include $\mathrm{KM}$ as a risk management strategy, KM to build employee engagement, and also a knowledge sharing culture. The least reported KM activities were calculating ROI on KM, a focus on IC as a driver of IP, and curiously, as a means of capturing tacit forms of knowledge. On deeper analysis, this appeared to reflect a dominant focus on tangible rather than intangible forms of knowledge across all six organizations.

Respondents from all six organizations were strongly in agreement that KM provided strong support for business excellence endeavors and contributed to innovation. However, some factors were identified as being critical success factors linked closely to the principles of the ABEF and included:

- $\quad$ Linking KM to business strategy

- Linking technology to people and processes

- Gaining the support of senior management

- Focusing on the needs of clients and/or customers

- Implementing two-way and open communication processes

- Sharing knowledge across the organization

- Rewarding knowledge work

- Planning processes that crosscuts all business units and/or divisions.

- Creating a common language of KM

It is interesting to note that for most of the organizations, the definition and scope of innovation was limited to incremental rather than radical or large scale innovation. In all six cases, a strong emphasis on innovation based within the organizational culture as opposed to innovation based within value-chains was evident. The public sector organizations in particular focus strongly on continuous improvement in an environment where providing high quality service and delivering greater value to stakeholders drives KM and innovation. In contrast, the two private sector organizations view innovation as a source of direct competitive advantage through the discovery of new techniques, the development of new products and services as well as the improvement of existing services through continuous improvement.

It is also of interest to note that all six case study organizations had a strong focus and often a long 
history of quality and continuous improvement, Six Sigma or TQM. This focus may have prompted their use of the ABEF in the first instance. Given that background, it is not surprising that innovation was regarded more in an incremental rather than radical context. While it is likely that incremental forms of innovation will lead to IP and contribute to overall business performance, IP does not always result in business performance. However, we would argue that $\mathrm{KM}$ can add value to business operations overall and clearly this occurs in terms of KM supporting business excellence and incremental forms of innovation. The paradox here is that if radical forms of innovation are not entertained and supported by KM, might these organizations be eclipsed by other competitors engaging in more radical forms of innovation?

\section{Conclusion}

As competition in business and industry continues to grow, the demand for effective KM to support innovation in knowledge-intensive industries also increases. In this context, the strong links between forms of knowledge and modes of innovation motivate organizations to manage their knowledge assets proactively to achieve IP. To this end, the manner in which organizations approach KM influences IP. Business excellence frameworks can be useful in shaping KM activities to support IP; however, this early stage research has indicated that the nature of business excellence frameworks, with their roots in quality and continuous improvement, may actually place a heavier focus on incremental rather than more radical forms of innovation. This research is preliminary in nature and it would be useful to expand the number of cases and to examine other business excellence frameworks. For instance, the U.S. Baldrige Awards contain a strong focus on KM, so this will be one thrust of future research in this area.

\section{References}

[1] Du Plessis, M. (2007), "The role of knowledge management in innovation", Journal of Knowledge Management, 11(4), pp. 20-9.

[2] Heisig, P. (2009), "Harmonisation of knowledge management - comparing $160 \mathrm{KM}$ frameworks around the globe", Journal of Knowledge Management, 13(4), pp. 4-31. [3] Prahalad, C.S. and Krishnan, M.S. (2008), The New Age of Innovation: Driving Co-created Value through Global Networks, McGraw-Hill, New York.

[4] Jorna, R. (2006), Sustainable Innovation: The Organisational, Human and Knowledge Dimension, Greenleaf Publishing, Sheffield.

[5] McAdam, R. (2000), "Knowledge management as a catalyst for innovation within organizations: a qualitative study", Knowledge and Process Management, 7(4), pp. 23341.

[6] Cohen, J. F., \& Olsen, K. (2015), "Knowledge management capabilities and firm performance: A test of universalistic, contingency and complementarity perspectives", Expert Systems with Applications, 42(3), pp.1178-1188

[7] Acedo, F., Barroso, C. and Galen, J. (2006), "The Resource-Based Theory: Dissemination and Main Trends". Strategic Management Journal, 27(7), pp. 621-36.

[8] Teece, D. (1998). "Capturing Value from Knowledge Assets: the new economy, markets for know-how and intangible assets". California Management Review, 40(3), pp. 55-79.

[9] Penrose, E. (1959). The Theory of the Growth of the Firm, John Wiley, New York.

[10] Wernerfelt, B. (1984). "The Resource-Based View of the Firm”, Strategic Management Journal, 5(2), pp.171-80. [11] Barney, J. (1991). "Firm Resources and Sustained Competitive Advantage". Journal of Management, 17(1), pp. 99-119.

[12] Barney, J. (1996). "The Resource-Based Theory of the Firm”. Organization Science, 7(5), pp. 469-76.

[13] Barney, J., 2001. "Is the resource-based 'view' a useful perspective for strategic management research? Yes." Academy of Management Review, 26(1), pp. 41-56.

[14] Armstrong, C. (2007). "A Review of Approaches to Empirical Research on the Resource-Based View of the Firm". Journal of Management, 33(6), pp. 959-986.

[15] Teece, D. (2009). Dynamic Capabilities and Strategic Management: Organizing for Innovation and Growth. Oxford: Oxford University Press.

[16] Heisig, P. and Vorbeck, J. (2001), "Benchmarking survey results", in K. Mertins, P. Heisig and J. Vorbeck, J. (eds), Knowledge management: Best Practices in Europe, Springer Verlag, Berlin.

[17] Levy, J.D. (2003), "Creating a Change Management Knowledge Infrastructure", Information Management and Consulting, 18(1), pp. 12-16.

[18] Hasan, H. and Handzic, M. (eds) (2003), Australian Studies in Knowledge Management. Wollongong University Press, Wollongong.

[19] Gloet, M. and Samson, D. (2012). "Knowledge Management and Innovation Performance in Australian Service Sector Organizations". Proceedings of the $45^{\text {th }}$ Hawaii International Conference on System Sciences (HICSS), January.

[20] Oakland, J. S., 2014. Total quality management and operational excellence: text with cases. Routledge. [21] Botha, A., Kourie, D. and Snyman, R. (2014). Coping with continuous change in the business environment: knowledge management and knowledge management technology. Elsevier.

[22] Para-González, L., Jiménez-Jiménez, D. and MartínezLorente, A. (2015). "The importance of intellectual capital in the EFQM model of excellence." European Conference on Intellectual Capital. Academic Conferences International Limited. 
[23] Moradi, M, Rahim, M. Maisam, S. (2011). "Knowledge Mapping Based on EFQM Excellence Model: A Practical Tool to Make Visible Organizational Knowledge". Proceedings of the European Conference on Knowledge Management, Vol. 2, pp. 668-675.

[24] Schiuma, G. and Lerro, A. (2008), "Knowledge-based capital in building regional innovation capacity", Journal of Knowledge Management, 12(5), pp. 121-36.

[25] BEA, 2003. Available from

https://www.saiglobal.com/improve/excellencemodels/busi nessexcellenceframework/

[26] Ryan, A. (2010), "Innovation Performance", White Paper No. 1 on Innovation Performance, available at http://www.managedinnovation.com/articles.

[27] Adams, R., Neely, A., Yaghi, B. and Bessant, B. (2008). Proposal for Measures of Firm-Level Innovation Performance in 12 Sectors of UK Industry, an Innovation Index Working Paper, National Endowment for Science Technology and the Arts [NESTA], London.

[28] Neely, A. (ed.) (2002). Business Performance Measurement: Theory and Practice. Cambridge University Press, Cambridge.

[29] Gloet, M. and Samson, D. (2013), "Knowledge Management to Support Systematic Innovation Capability", Proceedings of the 46th Hawaii International Conference on the System Sciences, January.

[30] Keupp, M., Palmie, M. and Gassmann, O. (2012),

"The Strategic Management of Innovation: A Systematic

Review and Paths for Future Research", International Journal of Management Reviews, 14, pp. 367-390.

[31] Makri, M. and Scandura, T. (2010), "Exploring the effects of creative CEO leadership on innovation in hightechnology firms", The Leadership Quarterly, 21, pp.75-88. [32] Paulsen, N., Callan, V. and Ayoko, O. (2013), "Transformational leadership and innovation in an R\&D organization experiencing major change", Journal of Organizational Change Management, 26(3), pp. 595-610.

[33] Chiaroni, D., Chiesa, V. and Frattini, F. (2011), "The Open Innovation Journey: How firms dynamically implement the emerging innovation management paradigm", Technovation, 31, pp. 34-43.

[34] Sawhney, M., Verona, G. and Prandell, E. (2005), "Collaborating to create: the Internet as a Platform for Customer Engagement in Product Innovation", Journal of Interactive Marketing, 19(4), pp. 1-15.

[35] Lopez-Cabrales, A., Perez-Luno, A. and Cabrera, R. (2009), "Knowledge as a Medaitor Between HRM Practices and Innovative Activity", Human Resource Management, 48(4), pp. 485-503.

[36] Chen, C. and Huang, J. (2009), "Strategic human resource practices and innovation performance - the mediating role of knowledge management capacity", Journal of Business Research, 62, pp. 104-114.

[37] Mu, J., Peng, G. and MacLachlan, D. (2009), "Effect of risk management strategy on NPD performance", Technovation, 29, pp. 170-180.

[38] Jimenez-Jimenez, D. and Sanz-Valle, R. (2011), "Innovation, organizational learning, and performance", Journal of Business Research, 64, pp. 408-417.

[39] Foss, N., Laursen, K. and Pederson, T. (2011), "Linking Customer Interaction and Innovation: The Mediating Role of New Organizational Practices", Organization Science, 22(4), pp. 980-999.

[40] Kong, E., Doren, C. and Raman, R. (2011), "The role of human resource practices in developing knowledge and learning capabilities for innovation: A study of IT service providers in India", in 10th International Research Conference on Quality, Innovation and Knowledge Management: Aligning Innovation in Developed and Emerging Economies (QIK 2011), 15-18 Feb 2011, Kuala Lumpur, Malaysia.

[41] Gavronski, I., Klassen, R., Vachon, S., Maschado do Nascimento, L. (2012), "A learning and knowledge approach to sustainable operations", International Journal of Production Economics, 140, 183-192.

[42] Quist, J. and Tukker, A. (2013), "Knowledge collaboration and learning for sustainable innovation and consumption: introduction", Journal of Cleaner Production, 48, pp. 167-175.

[43] Melville, N. (2010), "Information Systems Innovation for Environmental Sustainability", MIS Quarterly, 34(1), pp. $1-21$.

[44] Darroch, J. (2005), "Knowledge management, innovation and firm performance", Journal of Knowledge Management, 9(3), pp. 101-115.

[45] Pagani, M. (2013), "Digital Business Strategy and Value Creation: Framing the Dynamic Cycle of Control Points". Mis Quarterly, 37(2), 617-632.

[46] Sanz-Valle, R., Naranjo-Valencia, J., Jimenez-Jimenez, D. and Perez-Caballero, L. (2011), "Linking organizational learning with technical innovation and organizational culture", Journal of Knowledge Management, 15(6), pp. 997-1015.

[47] Ahmad, S. and Schroeder, R. (2011), "Knowledge management through technology strategy: implications for competitiveness", Journal of Manufacturing Technology Management", 22(1), pp. 6-24.

[48] Kim, D., Kumar, V. and Kumar, U. (2012), "Relationship between quality management practices and innovation", Journal of Operations Management, 30, pp. 295-315.

[49] Lin, R., Chen, R. and Chiu, K. (2010), "Customer relationship management and innovation capability: an empirical study", Industrial Management and Data Systems, 110(1), pp. 111-130.

[50] Chua, A. Y. and Banerjee, S. (2013), "Customer knowledge management via social media: the case of Starbucks". J of Knowledge Management, 17(2), 237-249. [51] Khodakarami, F., \& Chan, Y. E. (2014), "Exploring the role of customer relationship management (CRM) systems in customer knowledge creation. Information \& Management, 51(1), pp. 27-42.

[52] Yin, R.K. (2014), Case study research: design and methods, $5^{\text {th }}$ ed., Sage, Thousand Oaks.

[53] Merriam, S. (1998). Qualitative research and case study applications in education. Jossey Bass, San Francisco.

[54] Miles, M. B., Huberman, A. M., \& Saldana, J. (2014). Qualitative Data Analysis: A Methods Sourcebook ( $3^{\text {rd }} \mathrm{ed}$ ). Thousand Oaks, California: SAGE Publications, Inc. [55] Recker, J. (2013). Scientific research in information systems : a beginner's guide. Springer Berlin Heidelberg. 